\title{
PASCAL: O CARTESIANO CRÍTICO DE DESCARTES
}

\author{
José da Cruz Lopes Marques ${ }^{1}$ \\ Universidade Federal do Ceará (UFC)
}

\begin{abstract}
RESUMO:
As interpretações referentes ao relacionamento entre Blaise Pascal e Renné Descartes costumam situar-se entre dois extremos. Algumas vezes, o autor dos Pensamentos é interpretado como uma espécie de cartesiano indeciso, incapaz de separar o seu discurso religioso das investigações científicas e filosóficas. Outras vezes, Pascal é estereotipado como uma espécie de anticartesiano empedernido, um apologista cuja fé não pode evitar o racionalismo. O presente busca evitar estas duas compreensões, tentando encontrar um Pascal que foi cartesiano em certa medida, mas, ao mesmo tempo, crítico de Descartes, sem que, contudo, tal crítica justifique a acusação de irracionalismo.
\end{abstract}

PALAVRAS-CHAVE: Modernidade; Racionalismo; Método; Pascal; Descartes.

\section{PASCAL: THE CARTESIAN CRITIC OF DESCARTES}

\begin{abstract}
:
The interpretations regarding the relationship between Blaise Pascal and Descartes Renné usually be between two extremes. Sometimes, the author of Thoughts is interpreted as a sort of Cartesian indecisive, unable to separate his religious discourse of the scientific and philosophical investigations. Other times, Pascal is stereotyped as a kind of anti-Cartesian obdurate, an apologist whose faith cannot avoid rationalism. This seeks to avoid these two understandings, trying to find a Pascal was Cartesian to some extent, but at the same time critical of Descartes, without, however, such criticism justifies the accusation of irrationalism.
\end{abstract}

KEYWORDS: Modernity; Rationalism; Method; Pascal; Descartes.

\footnotetext{
${ }^{1}$ Doutorando em Filosofia pela Universidade Federal do Ceará (UFC), Ceará - Brasil. Orientador: Evanildo Costeski. E-mail: markvani18@yahoo.com.br
} 


\section{Considerações iniciais}

Em 23 e 24 de setembro de 1647 registra-se o emblemático encontro entre dois grandes expoentes do pensamento moderno. Em visita à França, Descartes, já com a sua experiência cinquentenária, dialoga com Pascal, um gênio precoce de saúde frágil que, aos 24 anos, podia celebrar a autoria de obras importantes como o Ensaio sobre as cônicas e as Experiências novas referentes ao vácuo. De fato, a sua genialidade era tamanha que, aos 12 anos, ele aprendera sozinho as 32 proposições da geometria euclidiana. Embora a conversa entre estes dois importantes filósofos não tenha alcançado muita notoriedade à época, ela foi alvo de muita reflexão posterior. Costumeiramente, todos aqueles que empreendem um confronto entre Descartes e Pascal, geralmente, fazem alusão a esse célebre encontro. De forma inusitada, esse acontecimento foi tema de uma peça teatral denominada Encontro entre Descartes e o jovem Pascal, de autoria do dramaturgo francês Jean-Claude Brisville. Embora a peça de Brisville fundamente-se em muitos trechos isolados destes filósofos, a sua reconstrução é tendenciosa, pois recria em Pascal uma espécie de místico fanático que rejeita em extremo o papel da razão em nome de suas convicções religiosas. Além do irracionalismo, o Pascal de Brisville possui um temperamento excêntrico e precipitado. Descartes, por outro lado, é pintado como o sábio maduro que destila prudência em cada palavra, o cidadão cosmopolita notável por sua tolerância religiosa e aceitação às ideias contrárias, o homem equilibrado que consegue dedicar-se à ciência sem renunciar as suas crenças religiosas.

Há duas concepções extremadas sobre a interpretação do pensamento de Pascal. Por um lado, há aqueles que veem no pensador francês uma espécie de fideísta que renunciava por completo o papel da razão tanto nas discussões acerca da fé quanto no contexto da pesquisa científica. Tal conclusão apoia-se, sobretudo, na crítica feita por Pascal a Descartes no que diz respeito aos limites da razão. Por outro lado, há aqueles que reduzem o autor dos Pensamentos a um cartesiano disfarçado. Reivindicam a seu favor a primazia dada ao pensamento pelo filósofo de Clermont-Ferrand. Usa-se, com frequência, a sua famosa definição do homem como o "caniço pensante", herdeira do racionalismo cartesiano. A proposta central desse artigo visa trazer a lume a interpretação mais equilibrada de um Pascal que foi, ao mesmo tempo, cartesiano e crítico de Descartes, um filósofo que reconheceu a grandeza da razão, mas não deixou de denunciar os seus limites.

\section{O Pascal cartesiano}

À guisa de consideração preliminar, cabe ressaltar que o termo cartesiano será empregado aqui não querendo sugerir que Pascal foi um 
adepto deste sistema de pensamento em sua inteireza, mas para ressaltar que muitos conceitos importantes esboçados por Descartes são endossados pelo polemista de Port-Royal. Provavelmente, é partindo desta compreensão que André Vergez e Denis Huisman denominam Pascal de "verdadeiro cartesiano" (VERGEZ; HUISMAN, 1982). O cartesianismo foi uma filosofia marcante ao longo do século XVII, de modo que não é incomum encontrar resquícios deste sistema, mesmo naqueles pensadores que adotaram uma postura crítica em relação ao autor das Paixões da alma.

\title{
0 caniço pensante
}

\begin{abstract}
O homem é visivelmente feito para pensar, é toda a sua dignidade e todo o seu mérito; e todo o seu dever consiste em pensar corretamente (...). Posso conceber um homem sem mãos, pés, cabeça, mas não posso conceber um homem sem pensamento: seria uma pedra ou um animal (PASCAL, Pensamentos).
\end{abstract}

Por meio de sua famosa doutrina do cogito Descartes já atribuíra um caráter elevado ao pensamento. O pensamento é, por assim dizer, elemento autenticador da existência. "Sou uma coisa que pensa", já declarara o filósofo francês em suas Meditações. A propósito, quatro anos antes comentando sobre o estabelecimento de um novo método para as ciências, Descartes já confessara que aquilo que mais lhe satisfazia era saber que o uso do seu método lhe permitiria o uso da razão em cada coisa (DESCARTES, 2004, p. 33). Pascal segue de perto a ideia cartesiana em relação ao valor do pensamento e da razão. Assim, constitui-se um equívoco primário concluir que o autor das Cartas provinciais tenha advogado qualquer forma de irracionalismo filosófico, semelhante àquele que se encontra na peça de Brisville. Em muitos diálogos recriados pelo dramaturgo francês, percebe-se esta incongruência:

DESCARTES: Se temos uma grandeza ela está, para mim, no exercício soberano do pensamento. Nele, apenas nele.

PASCAL: Como um pensamento que não consegue apreender seu objeto não confessaria nossa fraqueza? Ou é sua pretensão dominar o infinito... a eternidade? Seria pecar por orgulho.

DESCARTES: Não creio pecar tentando ir mais longe nas matemáticas, que me fazem pressentir uma representação do universo. O sistema do mundo talvez seja um sistema de números. É algum escândalo pensar nisso?

PASCAL: Teria a ambição de ser um construtor de um universo totalmente sujeito à geometria?

DESCARTES: Já que existe a mecânica lá em cima, eu gostaria de tentar seu cálculo.

PASCAL: É o único homem que o lograria. (BRISVILLE, 1985). 
O diálogo reproduzido por Brisville acima parece sugerir um Pascal em completo desacordo com Descartes no que diz respeito ao valor do pensamento. Cabe reiterar, não obstante, que tal conclusão não resiste a uma investigação mais acurada da concepção pascaliana. Em um das passagens mais conhecidas dos Pensamentos o filósofo jansenista desmente esta pretensão: "O homem não passa de um caniço, o mais fraco na natureza, mas é um caniço pensante. Mesmo que o universo o esmagasse, o homem seria ainda mais nobre do que quem o mata, porque sabe que morre e a vantagem que o universo tem sobre ele" (PASCAL, 2001, p. 122). O universo, com toda a sua magnitude, abarca o homem e o traga como a um ponto ínfimo, mas, por meio do pensar, o homem abarca todo o universo, no espaço de um instante ele é capaz de tragar e perscrutar a sua magnitude. O pensamento é, por assim dizer, aquilo que identifica o homem enquanto tal, o elemento sem o qual ele não pode ser pensado ou definido. Pode-se pensar um homem sem mãos, sem cabeça ou sem pernas, mas um homem desprovido da faculdade do pensar, não seria mais que um animal ou uma pedra. Ao "penso, logo existo" de Descartes, Pascal propõe o "penso, logo sou homem". De fato, o pensar é para o filósofo jansenista não apenas o elemento que confere dignidade ao homem, mas algo que possui um vínculo direto com a moralidade. Ao modo pascaliano, o esforço pelo bem pensar consiste em um importante princípio da moral. O homem, portanto, não deve buscar sua dignidade no espaço, na posse de riquezas, mas na ordenação do seu pensamento, no exercício frequente da razão.

Em sua obra póstuma Pensamentos Pascal lista dois elementos que caracterizam a natureza humana, a saber, o instinto e a razão. Tais elementos são como dois senhores que ordenam nossos atos. Para ser mais preciso, nas palavras do filósofo jansenista, a razão manda em nós muito mais imperativamente do que um amo, de tal forma que, tentar desobedecêla seria o cúmulo da tolice (PASCAL, 2001). Podemos, então, afirmar que Pascal é cartesiano ao assegurar a importância da razão e do pensamento. Se tomarmos como paradigma a compreensão antropológica do polemista de Port-Royal de que o homem é marcado por um grande princípio de grandeza e um grande princípio de miséria, temos, então que admitir que o pensamento é aquilo que realça a grandeza do homem. Quando morreu em 1662, Pascal deixou incompleta a sua Apologia da religião cristã, obra que ele começara escrever seis anos antes. Os apontamentos deixados pelo filósofo foram coletados, organizados e publicados em $1670 \mathrm{com}$ o sugestivo título de Pensamentos, Pensées em francês. Justo tributo a um filósofo que em vida tributou honra à grandeza do pensamento.

\section{0 fascínio pela ciência}


Os biógrafos costumam atribuir a Pascal duas experiências de conversão. A primeira refere-se à sua adesão ao jansenismo em 1646, a segunda, ao êxtase místico ocorrido na noite de 23 de novembro de 1654 , ocasião em que teria sido atingido por uma fulgurante iluminação divina (REALE: ANTISERI, 2007). Alguns supõem que, após estas experiências religiosas, o autor dos Pensamentos teria renunciado a sua intensa dedicação à pesquisa científica, como se a fé fosse uma espécie de obstáculo para sua investigação. "Já dei muito de mim para a ciência. Desde certo encontro que tive, sei que há coisas mais importantes e não quero me distrair", é o que afirma uma frase colocada de forma tendenciosa na boca de Pascal por Brisville. Embora esta conclusão tente encontrar fundamento no testemunho de Gilberte, irmã e primeira biógrafa de Pascal, os dados históricos atestam o seu caráter inverossímil. Após a chamada primeira conversão, o polemista de Port-Royal escreveu Novas experiências sobre o vácuo, Descrição da grande experiência do equilíbrio dos licores, o Tratado sobre o triângulo aritmético, dentre outras obras científicas importantes. Referindo-se a esta experiência de Pascal, Mauriac (1967, p. 17), lembra-nos que mesmo "após a iluminação dessa famosa noite, Pascal pode continuar assombrando o mundo com suas descobertas, escrever tratado sobre os sólidos circulares, resolver problemas de cálculo integral e abrir caminho para os criadores do cálculo infinitesimal". Mesmo após a sua segunda conversão, Pascal não abriu mão por completo da investigação científica. Prova disso é que em 1658, no auge de sua fase mística, ele escreveu e publicou estudos geométricos sobre a cicloide. Pode-se dizer que há em Pascal uma coexistência entre o cientista e o místico. O seu pensamento se nutre desses dois aspectos de sua vida, ao mesmo tempo que lhes dá fundamentação Francesco Paolo Adorno, em seu estudo sobre Pascal demonstra o caráter ambivalente do pensamento deste filósofo. Nas suas palavras,

Embora o fervor de Port-Royal exija que o interesse votado à religião seja absoluto, com exclusão de qualquer outro, e que, em consequência, ele limite as atividades sem ligação direta com ela - o que Pascal parece ter aceitado sem reservas - sua atividade de apologista e de controversista a serviço da "verdadeira religião" muitas vezes se cruza com sua atividade de cientista. Mesmo no momento da redação dos documentos que deviam compor a Apologia da religião cristã, ele se dedica à geometria, a tal ponto que lança o concurso sobre a roleta, o qual deveria parecer verdadeiramente escandaloso e principalmente contraditório em Port-Royal. (ADORNO, 2008, p. 21).

É verdade que, como ressalta Eymar (2010), por conta de sua figura taciturna, sua predileção pela ascese e sua renúncia rigorosa aos prazeres mundanos, o caráter moderno do pensamento de Pascal tem sido rechaçado por alguns estudiosos. Esta é, por exemplo, a tendência de Hans Kung, ao 
reduzir o polemista de Port-Royal a um pensador medieval, um prémoderno não no sentido do que antecipa a modernidade, mas daquele que a contrapõe. Ou mesmo Kolakowski que vê em Pascal o asceta que prega o ódio ao corpo. Em uma espécie de argumentum ad hominem, tenta-se suprimir o valor do filósofo e cientista com base na sua devoção religiosa. É preciso reiterar que tal suposição carece de senso. Guardadas as devidas proporções, seria como afirmar que o racionalismo de Descartes lhe impediu de crer e postular a existência de Deus.

É bem verdade que os métodos humanos não são infalíveis no entender de Pascal. Tal compreensão já fora demonstrada por Étienne Pascal. Por ocasião da publicação do Discurso do método, o patriarca da família Pascal colocara-se claramente em oposição às pretensões cartesianas. Não obstante, o autor das Provinciais não renuncia ao método em sua radicalidade. De fato, ele divide o seu método em três partes, a saber: as definições, os axiomas e as demonstrações. As definições devem ser claras e inequívocas, além de basearem-se em conceitos previamente estabelecidos. Quase ouvimos Descartes sussurrando em seu Discurso do método a sua regra de não aceitar como verdadeiro aquilo que não conhecesse claramente como tal (DESCARTES, 2004). Os axiomas, por sua vez devem corresponder aos princípios que são evidentes para todos, as demonstrações, por fim, devem se utilizar somente de axiomas evidentíssimos e de proposições já demonstradas e admitidas (MUÑOZ, 2003). Nada mal para um filósofo, às vezes, repudiado por seu irracionalismo.

\section{Fé além da razão, mas não sem razão}

É clara em Descartes à recorrência às provas racionais para o estabelecimento da existência de Deus. É o que pode ser percebido na apropriação cartesiana do argumento ontológico para a existência de Deus. Por meio dessa argumentação a priori, já utilizada por Anselmo no século XI, Descartes manifesta a sujeição das questões de fé ao exercício da razão. Por manifestar-se contrário à pretensão cartesiana, Pascal é interpretado, algumas vezes, como aquele que despreza a razão em absoluto, anatematizando o uso dessa faculdade nas considerações acerca da fé. É mister conservar a cautela, pois, mesmo neste tópico, o desacordo entre os dois filósofos não é tão radical. É verdade que o autor dos Pensamentos foi um crítico declarado das provas tomistas para a existência de Deus. Flores e passarinhos não demonstram Deus, diria. Mas disso não deve ser concluído que Pascal tenha rejeitado qualquer possibilidade de aproximação entre fé e razão. O homem, dirá o filósofo jansenista, será levado a crer se ouvir corretamente a voz de sua razão (PASCAL, 2001). Mas em que sentido a razão pode ser útil à fé, segundo o pensamento pascaliano? 
Antes de tudo, dirá o filósofo francês, a razão serve para barrar o apelo do divertimento, a fim de que o homem possa compreender a sua própria miséria. $\mathrm{O}$ conceito de divertissement (divertimento) em Pascal não se restringe a ideia de diversão ou entrega ao prazer. $\mathrm{O}$ termo tem o sentido de distração, uma espécie de fuga que impede o homem de pensar a sua própria condição. Neste sentido, tanto a entrega aos prazeres quanto o ativismo podem vistos como frutos dessa atitude (ABBAGNANO, 2007, p. 342). O homem entregue ao divertissement, dirá Pondé (2014, p. 25), "foge de si mesmo dissolvendo sua interioridade na paixão da criatura". Em um trocadilho, o divertissement di-verte, desvia da tomada de consciência. Ao mesmo tempo, dirá Pascal, o divertissement é uma espécie de alívio enganoso para a miséria do homem. O divertissement, contudo, possui um caráter contraditório. Ao mesmo tempo em que se oferece como remédio para a nossa miséria, ele se converte na maior de todas as misérias, posto que nos priva de pensar nossa própria condição (PASCAL, 2001). A razão, portanto, denuncia o caráter fugaz do divertissement, preparando o caminho para a fé.

Ademais, a razão serve para que o homem possa avaliar em que medida a fé dá sentido a existência. Embora a fé encontre-se na esfera do mistério, do ocultamento, em muitos trechos dos Pensamentos, Pascal convida o leitor a arrazoar sobre o modo como a fé se coloca como uma explicação plausível para o ministério. É preciso razão, se não para compreender a fé, pelo menos, para se apavorar ao contemplar o silêncio eterno dos espaços infinitos (PASCAL, 2001). Um exemplo que merece ser aludido nesse contexto é, sem dúvida, aquilo que o autor das Provinciais designa Mistério do pecado original. Sobre esse ponto Pascal se antecipa em ressaltar que, do ponto de vista racional, a doutrina do pecado original é inexplicável, mas, na sequência convida o seu leitor a arrazoar que, sem ela, a própria existência seria inexplicável. Sem ela, no seu entender, não haveria explicação suficiente para todos os males que afligem a humanidades (MONDIM, 1981, p. 83). Se é verdade que Pascal é um crítico severo do reducionismo da religião à razão, não é menos verdade que rejeita veementemente a eliminação da razão do contexto religioso. Nos termos do pensador francês:

"Se submetermos tudo à razão, a nossa religião não terá nada de misterioso e de sobrenatural. Se violentarmos os princípios da razão, nossa religião será absurda e ridícula" (PASCAL, 2005, p. 71). Mesmo a crítica à razão, deve ser feita racionalmente e não abrindo espaço para o ceticismo e para o irracionalismo.

Por fim, a razão tem sua utilidade para fé, pois leva o homem a apostar na existência de Deus. Ela demonstra que, diante das possibilidades de perdas e ganhos é muito mais satisfatório crer em Deus. Em seu famoso argumento da aposta, Pascal leva o seu leitor à seguinte reflexão: 


\begin{abstract}
Pesemos o ganho e a perda, apostando em Deus. Vejamos os dois casos: se ganhardes, ganhareis tudo; se perderdes, nada perdereis. Apostai, então, na sua existência sem a menor hesitação [...] Há uma infinidade de vida infinitamente feliz a se ganhar a ganhar, um acaso de ganho contra um número finito de acasos de perda; e o que jogais é finito. Isso afasta todo partido: onde quer que esteja o infinito, e onde não haja infinidade de acasos de perda contra o de ganho, não há o que pesar. É preciso dar tudo (PASCAL apud VERGEZ; HUISMAN, 1982, p. 311).
\end{abstract}

Para Pascal, embora Deus seja definido como o absconditus, a sua existência é razoável, no mínimo, mais provável. Para aqueles que veem no filósofo francês a figura do fideísta irracional, cabe um último questionamento: não seria uma demonstração clara de uso da razão utilizarse de um cálculo de probabilidades para argumentar acerca da existência de Deus?

\title{
O Pascal crítico de Descartes
}

É uma doença natural do homem julgar que ele possui a verdade diretamente; e disso decorre o fato de estar sempre disposto a negar tudo que lhe é incompreensível, ao passo que, com efeito, não só conhece naturalmente a mentira e que deve admitir por verdadeiras somente as coisas cujo contrário parece falso (PASCAL, Do espírito geométrico).

É o próprio Pascal que declara em seus Pensamentos que tanto a exclusão da razão como o reducionismo de tudo à razão são formas de excesso. Conforme visto no tópico anterior, o filósofo jansenista foi contrário ao primeiro excesso. A partir de agora, a pesquisa concentrar-se-á na crítica feita por ele à segunda forma de excesso, a saber: o reducionismo de tudo à razão. Precisamos admitir que Pascal se apropriou de algumas ideias cartesianas na construção do seu pensamento. Não obstante, é preciso ressaltar que o autor das Provinciais foi um dos mais decididos críticos de Descartes. Vergez e Huisman (1982) acreditam que o cartesianismo é uma espécie de ponto de partida de Pascal na construção do seu sistema filosófico. Não nos compete, por enquanto, examinar a veracidade de tal conclusão, ainda que não seja difícil, em muitos fragmentos dos Pensamentos, perceber o tom de sua crítica mordaz ao autor do Discurso do método.

\section{Deus invocado para fazer funcionar o sistema}

Em uma das passagens mais expressiva dos Pensamentos, Pascal dirige uma severa crítica ao empreendimento cartesiano: "Não posso perdoar Descartes; bem quisera ele, em toda a sua filosofia, mas não pode 
evitar de fazê-lo dar um piparote para por o mundo em movimento; depois do que não precisa mais de Deus" (PASCAL, 2001, p. 73). No entender de Pascal Descartes usa Deus apenas como um pretexto para fazer funcionar o seu sistema. Aparentemente, o sistema cartesiano privilegiava Deus, colocando-o como causa fundamental da existência, responsável, dentre outras coisas, pelas ideias eternas presentes na consciência humana. Tal engodo é denunciado por Pascal. Na verdade, segundo sua compreensão, Deus é colocado em segundo plano na filosofia de Descartes. Se pudesse fazer seu sistema funcionar sem recorrer a Deus, era exatamente isso que teria feito. A crítica pascaliana é quase uma declaração de que Descartes foi um trapaceiro. Deus só foi invocado para servir de avalista de uma concepção de mundo que o cogito, abandonado a si mesmo, era incapaz de sustentar (ABRÃO, 2004).

O esforço cartesiano no sentido de demonstrar racionalmente a existência de Deus é bem conhecida a partir das Meditações, texto no qual Descartes empreende uma reformulação do famoso argumento ontológico desenvolvido por Santo Anselmo. No cerne da argumentação cartesiana encontra-se a impossibilidade de separação do conceito de Deus da ideia de perfeição. A rigor, Deus não é apenas um ser perfeito, Ele é perfeitíssimo no sentido de que contém em si a soma de todas as perfeições. É claro, não obstante, que a existência é uma forma de perfeição. Disso decorre que Deus não pode ser pensado como não existente. Noutros termos, se Deus não existisse, ele não seria sumamente perfeito, faltar-lhe-ia a existência, um atributo necessário à perfeição. Na concepção cartesiana, pode-se pensar em um cavalo alado que não exista na realidade, pois no conceito de cavalo alado não está implicada a ideia de perfeição absoluta, mas é impossível pensar Deus como inexistente. A verdade é que não nos é dada a liberdade de conceber um Deus sem existência, isto é, um ser supremamente perfeito sem uma suprema perfeição, como me é dada a liberdade de pensar um cavalo com asas ou sem asas (DESCARTES, 2004, p. 307). No comentário de Hamlyn (1990, p. 127) parafraseando o filósofo francês nas Meditações, "não podemos conceber Deus exceto como existente, da mesma maneira que não podemos conceber uma montanha sem um vale".

Uma leitura introdutória dos Pensamentos evidencia que Pascal vê com reservas o empreendimento cartesiano no sentido de encontrar provas racionais para a existência de Deus. Obviamente, é preciso evitar sempre a tentação de entender o famoso "Argumento da aposta" de Pascal como tendo o mesmo estatuto de prova ou demonstração no sentido cartesiano. Claramente, tal argumento situa-se na esfera da probabilidade e não da verdade indubitável. Rigorosamente falando, Pascal não empreende uma refutação específica da quinta meditação cartesiana. Sua crítica é, na verdade, mais abrangente, incluindo tanto provas a priori quanto $a$ posteriori. Não deixa, entretanto, de ser verdade que o princípio pascaliano segundo o qual não há uma relação necessária entre a definição de uma 
coisa e a afirmação do seu ser inviabilizaria o argumento de Descartes. Em suma, para Pascal, uma teologia que ousasse apoiar-se em argumentos racionais estaria fadada ao fracasso. A razão desse fracasso é explicada pelo polemista de Port-Royal no fragmento seguinte:

As provas metafísicas de Deus, acham-se tão afastadas do raciocínio dos homens e tão embrulhadas, que pesam pouco; e, mesmo que isso servisse para alguns, serviria apenas durante o instante em que vissem essa demonstração; mas, uma hora depois, receariam ter-se enganado (PASCAL, 2001, p. 153).

Como se vê no fragmento acima, Pascal percebe dois inconvenientes nas provas metafísicas. Em primeiro lugar, tais provas se aplicariam apenas a um número reduzido de pessoas, somente aqueles dotados de grande conhecimento intelectual e que tivessem em condições de exercitar o seu pensamento a fim perscrutarem mistérios tão elevados. Somente a estes o conhecimento de Deus seria acessível. No entanto, a experiência demonstra que, mesmo as pessoas mais incultas e simples, são capazes de crer na existência de Deus. De fato, "um filósofo pode dar provas da existência de Deus, um exegeta pode comentar textos das Escrituras sobre Deus, mas o conhecimento que ambos têm de Deus continua longe do Deus afirmado por Pascal" (GOUHIER, 2005, p. 48). Além disso, esse procedimento exigiria que tais indivíduos alcançassem tal disciplina que fossem capazes de visualizar a cada instante o conteúdo da demonstração, pois, qualquer lapso desse pensamento poderia brotar a dúvida, algo que, por definição, depõe contra a essência da prova. A fraqueza das provas racionais é corroborada pelo pensamento 242 da edição Brunschvicg:

Dizer a eles que lhes basta ver a mínima das coisas que lhes cercam para nelas verem Deus de modo patente e dar-lhe como única prova desse grande e importante assunto o curso da Lua e dos planetas, e pretender ter terminado a prova com tal discurso, isso é dar-lhe a ocasião de pensar que as provas da nossa religião são bem fracas, e vejo por razão e por experiência que nada é mais apropriado para fazer nascer neles o desprezo por ela (PASCAL, 2001, p. 106).

Segundo Pascal, há uma dupla falha para empreendimentos de tipo cartesiano que buscam estabelecer provas indubitáveis da existência de Deus. Em primeiro lugar, não há elementos na natureza que sejam capazes, por si só, de convencer aqueles que já se decidiram pelo ateísmo. Com isso Pascal sugere que o ateu sempre encontrará razões para não crer. De fato, a expressão "ateus empedernidos" empregada no pensamento 556 (Brunschvicg) aponta para a incapacidade deliberada de tais pessoas conhecerem a Deus. Além disso, para o pensador francês, qualquer conhecimento que não seja precedido pelo conhecimento de Cristo é completamente inútil. No comentário preciso de Gouhier (2005, p. 226) 
sobre esse pensamento, "o conhecimento de Deus sem Jesus Cristo é inútil, e pode até ser prejudicial, favorecendo o orgulho".

Por meio de provas, pode-se, no máximo chegar ao deísmo, pensamento que, para Pascal, é tão afastado da religião cristã quanto o próprio ateísmo. O Deus cristão, dirá o polemista de Port-Royal em sua relutância em se utilizar das provas, "não consiste num Deus simplesmente autor de verdades geométricas e da ordem dos elementos; essa é a porção dos pagãos e dos epicuristas" PASCAL, 2001, p. 161). Isso faz lembrar a clássica distinção feita no Memorial entre o Deus de Abraão, Isaque e Jacó e o Deus dos filósofos.

\section{Não há método infalível para as ciências}

Um das questões básicas que preocupou Descartes foi exatamente a descoberta de um método seguro para as ciências. Segundo ele, baseada na concepção aristotélica que marcara todo o pensamento medieval, a ciência não fizera grandes progressos. Influenciado por sua quase devoção pela matemática, Descartes procurou estabelecer uma metodologia que fosse unicamente baseada na razão e cujo fundamento fossem ideias claras e distintas, que pudesse fundamentar-se em verdades indubitáveis. Tal pretensão pode ser confirmada pela passagem das Regras para a orientação do espírito, na qual se lê: "Os objetos com os quais devemos nos ocupar são aqueles que nossas mentes parecem bastar para conhecer de maneira certa e indubitável" (DESCARTES, 2001, p. 75). Baseado na compreensão da existência de tais ideias é que Descartes desenvolverá a sua Matemática universal, capaz de abranger com exatidão todo o conhecimento. Em outra passagem das Regras, o filósofo de La Flèche declara que:

\footnotetext{
Deve haver uma ciência geral que explique tudo que se pode buscar no que concerne à ordem e à medida, sem as aplicar a uma matéria especial: essa ciência se designa não pelo nome que toma emprestado, mas pelo nome já antigo e recebido pelo nome de Matemática Universal, porque ela encerra tudo aquilo que fez dar às outras ciências a denominação de partes das Matemáticas (DESCARTES, 2001, p. 84).
}

Como que em uma espécie de ironia denunciando a pretensão cartesiana, Pascal declara: "Ardemos no desejo de encontrar uma plataforma firme e uma base última e permanente para sobre ela edificar uma torre que se erguerá até o infinito; porém, os alicerces ruem e a terra se abre até o abismo" (PASCAL apud ABRÃO, 2004, p. 205). Por não acreditar em um método infalível, diferente de Descartes, Pascal também defende uma variedade de métodos para a ciência.

Neste contexto, é preciso resistir à tentação extremamente sutil de equiparar o método geométrico empregado por Pascal com a mathesis 
universalis proposta por Descartes. Já foi mencionado acima que Pascal não adere a uma metodologia única, justamente porque, no seu entender, cada método é atravessado por limites epistêmicos. À luz desse pressuposto, a aproximação entre as duas metodologias seria completamente implausível. No comentário de Pondé (2004, p. 66), o método geométrico "trata-se, basicamente, de um sistema formal de convenções (definições) que busca o estabelecimento seguro de significados e suas consequências (geométricas) necessárias. Esse estabelecimento sustenta a validade local do sistema geométrico em questão".

A título de confrontação, pode-se apontar duas importantes distinções entre a matemática universal e o método geométrico. Em primeiro lugar, o método cartesiano tem a pretensão de remontar aos primeiros princípios, aos fundamentos do conhecimento, algo que certamente é impossível ao método pascaliano. Ademais, enquanto o primeiro é marcado pela universalidade e pela infalibilidade, o segundo possui limitações quanto à área de aplicabilidade e, ainda que possa postular certezas, estas certezas não estão no mesmo estatuto da indubitabilidade cartesiana. Falando sobre esta distinção metodológica entre Pascal e Descartes, Lebrun assevera que:

Longe de ser garantia de verdade ou sinal de nossa
comunicação com o Verbo divino, a clareza dos princípios é
pois relativa ao alcance limitado de nosso campo de visão. Os
princípios não são nunca primeiras verdades em si, mas
simplesmente proposições estrategicamente úteis que
decidimos adotar como fundamento da investigação - e
testemunham antes nossa miopia do que nossa penetração
(LEBRUN, 1983, p. 32. Grifo do autor).

As limitações epistemológicas que caracterizam as metodologias científicas, segundo Pascal, repousam na doutrina cristã do pecado original. Por conta do pecado, o fundamento infalível do conhecimento foi para sempre perdido, restando ao homem apenas um conhecimento provável e verossimilhante.

\section{As razões do coração}

Segundo uma das sentenças mais conhecidas de Pascal, "o coração tem razões que a razão não conhece" (PASCAL, 2001, p. 110). Esta declaração emblemática pode admitir duas conclusões importantes. Em primeiro lugar, percebe-se aí um ataque às pretensões cartesianas a explicações racionais. Através dela, os limites da razão são postos de forma evidente. Há pelo menos uma coisa que transcende às explicações racionais, algo que ultrapassa o limite das demonstrações lógicas. Trata-se das razões do coração. Em segundo lugar, há uma modalidade de compreensão de Deus e da própria existência mais privilegiada que a própria razão, a saber, o 
coração ou as razões do coração. Mas o que seriam as razões do coração propostas por Pascal? Claramente, elas não devem ser confundidas com razão no sentido cartesiano. Além disso, seria precipitado confiná-las ao mero sentimento. É bastante claro que estas razões estão em conexão com a fé, com a disposição para crer como a peça-mestra que desvenda o mistério da existência. A razão é incapaz de demonstrar Deus, somente o coração pode senti-lo. Nas palavras de Pascal (2001, p. 111) "é o coração que sente Deus, não a razão. Eis o que é a fé: Deus sensível ao coração, não a razão".

O objeto específico e abrangência do conceito de "coração" em Pascal é um tópico que tem suscitado certa controvérsia entre os estudiosos de Pascal. Gouhier, por exemplo, em seu clássico Pascal: Conversão e apologética ressalta a dimensão religiosa desse conceito, uma provável uma alusão à ideia empregada pelo salmista segundo a qual Deus inclina o coração do homem. Nos termos do estudioso francês, "o 'coração' é, portanto, a parte da alma que, no exterior da razão e dos sentimentos, pode receber de Deus o movimento que a dirige para ele e que, por isso mesmo, afasta-a de tudo quanto não é ele" (GOUHIER, 2005, p. 88). É óbvio que neste conceito, assim como em todo pensamento pascaliano, há forte influência da teologia cristã. Não obstante, é preciso evitar o equívoco de situar a noção pascaliana de coração apenas em sua dimensão volitiva e não entendê-la em um sentido epistemológico. Em Pascal, o coração também conhece e, de algum modo, um conhecimento superior àquele oriundo da razão. A propósito, o próprio Gouhier (2005) faz questão de esclarecer esses dois sentidos de "coração" em Pascal, pontuando que estes sentidos depõem contra a acusação de irracionalismo atribuída ao pensador francês.

Acontece que, mesmo quando tomada em seu sentido epistemológico, a noção pascaliana de "coração" parece acentuar o desacordo entre o pensador jansenista e a filosofia cartesiana. Tal entendimento pode ser corroborado por uma sugestiva passagem de Pascal nos Pensamentos. Nos seus termos, "conhecemos a verdade não apenas pela razão, mas também pelo coração; é desta última maneira que conhecemos os princípios, e é em vão que o raciocínio, que dela não participa, tenta combatê-los" (PASCAL, 2001, p. 110). A incapacidade da razão em demonstrar os princípios serve para humilhá-la ao denunciar a sua pretensão soberba de tudo conhecer. A razão que desejaria julgar sobre tudo, depara-se aí com seus limites. Contra Descartes, Pascal entende que a razão não possui o monopólio da certeza. No comentário de Lebrun (1983, p. 39), "a indemonstrabilidade dos princípios é, sem dúvida, um sinal não equívoco da nossa finitude. Mas a finitude, nela mesma, não faz tanto obstáculo ao saber quanto o desconhecimento da finitude, cujo efeito principal é o delírio da razão". O primado do coração em relação à razão é posto com muita clareza do pensamento 282 da edição Brunschvicg no qual Pascal (2001) afirma que é o primeiro e não a segunda que sente que há três dimensões no espaço e que os números são infinitos. Curiosamente, ainda que o pensador jansenista 
postule o pensamento como aquilo que aponta para a grandeza do homem, para a sua dignidade, esta grandeza, paradoxalmente, precisa ao mesmo tempo ser contrabalanceada pela sua fraqueza, pelos seus limites.

Falamos anteriormente que a razão pode ser vista como uma manifestação do princípio de grandeza presente no homem, não obstante, é necessário também seguir Pascal quando a firma que a maior da grandeza da razão está em reconhecer a sua baixeza, os seus limites. A propósito, Pascal vê como um sinal de honestidade do cristão reconhecer que sua crença não pode ser reduzida à razão. Paradoxalmente, bem no espírito da antropologia pascaliana, há, mesmo na razão, indícios da miséria da homem. Claramente, essa compreensão do estatuto da razão em Pascal tem como contexto as doutrinas cristãs da criação e da queda. Criado segundo a imagem e semelhança da Divindade, o homem é um ser racional expressando a inteligência do seu criador, fato que demonstra a sua dignidade e grandeza. No entanto, após a queda, tudo no homem foi corrompido, inclusive sua razão, fato que atesta a sua condição de miséria. Adorno $(2008$, p. 41) capta essa tensão da antropologia pascaliana nos seguintes termos:

Essa mudança de centro do desejo é também fonte de uma desordem que atinge todos os planos do ser humano. No interior do homem, a razão é atingida. Se, no estado de perfeição, a razão, que encontrava a sua fonte na luz comunicada por Deus, estava em condições de guiar todas as faculdades de Adão, no estado de pecado, doravante, ela se deixa guiar pelos sentidos em busca do prazer.

\section{Considerações finais}

Que é o homem na natureza? Pergunta-se Pascal aturdido pelo sufocante paradoxo que envolve a existência. Poderíamos, parafraseando o filósofo francês, nos perguntar? Quem foi Pascal na filosofia. E a resposta é novamente paradoxal, à melhor maneira pascaliana. Pascal foi um dos mais modernos anti modernos, ao mesmo tempo, cartesiano e crítico de Descartes, bebeu suas influências e repudiou suas ideias. Diríamos ainda que talvez tenha sido ele que falou com maior sobriedade das grandezas e misérias da razão, talvez o primeiro a protestar contra o reducionismo da fé à razão.

$\mathrm{O}$ autor das Cartas provinciais foi cartesiano na medida em que ratificou muitas teses já defendidas pelo filósofo de La Haye. Como seu contemporâneo, Pascal foi opositor ferrenho do pensamento escolástico, chegando a rechaçar a prova tomista para a existência de Deus, a separação entre pensamento e natureza, além de ressaltar a importância da razão. Como seu compatriota mais velho, Pascal fez estudos sobre o vácuo e tinha predileção pela Geometria. Há de se notar, não obstante, que Pascal revelase um crítico ardoroso de Descartes, principalmente, ao acentuar os limites 
da razão. A razão nem sempre é razoável, diria em tom paradoxal. Segundo Pascal, a maior grandeza da razão está em reconhecer que há uma infinidade de coisas que a ultrapassam. Por fim, em relação às provas racionais para a existência de Deus, defende que é o coração que sente Deus não a razão. A fé consiste em um Deus sensível ao coração e não demonstrável pela razão. 


\section{Referências bibliográficas:}

ADORNO, Francesco Paolo. Pascal. Col. Figuras do saber. São Paulo: Estação Liberdade, 2008.

ATTALLI, Jacques. Blaise Pascal ou o gênio francês. Bauru: EDUSC, 2003.

BRISVILLE, Jean-Claude. Encontro entre Descartes e o jovem Pascal. Disponível em http://www.scielo.br/scielo.php (Acessado em 20 de setembro de 2015).

EYMAR, Carlos. Descartes y Pascal, um debate cristiano em la entraña de la modernidade. Revista de espiritualidad. Madrid. v. 69, p. 189 - 224, 2010.

GOUHIER, Henri. Blaise Pascal: conversão e apologética. São Paulo: Discurso Editorial, 2005.

DESCARTES, René. Discurso do método e regras para orientação do espírito. São Paulo: Martin Claret, 2001.

. Meditações. In: Os pensadores. São Paulo: Nova Cultural. 2004.

HAMLYN, Walter. Uma história da filosofia ocidental. Rio de Janeiro: Jorge Zahar Editor, 1990.

LEBRUN, Gerard. Blaise Pascal: voltas, desvios e reviravoltas. São Paulo: Brasiliense S. A., 1983.

MAURIAC, François. O pensamento vivo de Pascal. Col. Biblioteca do pensamento vivo. São Paulo: Martins, 1967.

MONDIM, Batistta. Curso de filosofia, 03 volumes. 6. ed. São Paulo: Paulus, 1983.

PASCAL. Oeuvres completes. Paris: Gallimard, 1954.

Pensamentos. Rio de Janeiro: Ediouro, 2001.

Pensamentos. 2. ed. São Paulo: Martins Fontes, 2005.

PONDÉ, Luiz Felipe. Conhecimento na desgraça: ensaio de epistemologia pascaliana. São Paulo: EDUSP, 2004.

. O homem insuficiente: comentários de antropologia pascaliana. São

Paulo: EDUSP, 2014.

REALE, Giovanni: ANTISERI, Dario. História da filosofia (7 volumes). São Paulo: Paulus, 2003.

SILVA, Franklin Leopoldo. Fé e razão na Apologia da religião cristã de Pascal. Cadernos de história da filosofia. Campinas. v. 11, n. 1, p. 29 - 44, 2001.

VERGEZ, André e HUISMAN, Dênis. História dos filósofos ilustrada pelos textos. Rio de Janeiro: Biblioteca universitária Freitas Bastos, 1982. 